\title{
Mutational and expression analysis of ELIP1 and ELIP2 in Arabidopsis thaliana
}

\author{
Anna Paola Casazza ${ }^{1 *}$, Silvia Rossini ${ }^{1}$, Mario G. Rosso ${ }^{2}$ and Carlo Soave ${ }^{1,3}$ \\ ${ }^{1}$ Dip. Biologia, Università degli Studi di Milano, Italy (*author for correspondence; e-mail anna.casaz- \\ za@unimi.it); ${ }^{2}$ GABI-Kat, Max Planck Institute for Plant Breeding Research, Köln, Germany; ${ }^{3}$ Division \\ Research of Milano Institute of Biophysics, C.N.R. Milano, Italy
}

Received 22 October 2004; accepted in revised form 20 March 2005

Key words: Arabidopsis thaliana, chloroplast, elip1 and elip2 mutants, gene expression, light and cold stress

\begin{abstract}
Plants exposed to photoinhibitory conditions respond by accumulation of the early light-induced proteins (ELIPs) with a potential photoprotective function. In Arabidopsis thaliana two genes (Elip1 and Elip2) encode for two ELIP proteins: evidence exists that the two genes are differentially regulated but their precise function is unclear. Mutants null for one or the other Elip gene can help in elucidating ELIPs role and here we describe the expression profile of ELIP1 and ELIP2, and the phenotype of such null mutants. Both ELIPs accumulate during greening of etiolated seedlings and in mature plants the transcripts fluctuate diurnally without protein accumulation. Steady-state transcript level of both genes increases in response to high light with transcription of Elip1 much more sensitive than that of Elip2 to increasing irradiation at $22{ }^{\circ} \mathrm{C}$. At $4{ }^{\circ} \mathrm{C}$ instead Elip2 is strongly transcribed even at growing light. Furthermore, only ELIP1 accumulates under high light at $22{ }^{\circ} \mathrm{C}$ while both proteins accumulate at $4{ }^{\circ} \mathrm{C}$. These results indicate the existence of a differential regulation of ELIPs expression in response to light or chilling stress with mechanisms active either at transcriptional and post-transcriptional level. Phenotypically, the mutants behave as the wild type as far as sensitivity to light- or light and cold-induced short-term photoinhibition, while both ELIPs are necessary to ensure a high rate of chlorophyll accumulation during deetiolation in continuous high light.
\end{abstract}

Abbreviations: ABA, abscisic acid; CAB, chlorophyll $a / b$-binding protein; chl $a / b$, chlorophyll $a / b$ ratio; Col-0, Columbia; ELIP, early light inducible protein; GST, glutathione S-transferase; HL, high light; LB, left border; LHC, light-harvesting complex; LL, low light; PCR, polymerase chain reaction; RT-PCR, reverse transcriptional-PCR; SDS, sodium dodecyl sulfate

\section{Introduction}

Light provides energy for photosynthetic $\mathrm{CO}_{2}$ assimilation: however, when plants absorb light in excess of the photosynthetic capacity, reactive $\mathrm{O}_{2}$ species are generated, causing oxidative damage to proteins, lipids and photosynthetic pigments. The damage is enhanced by concomitant environmental conditions (cold, drought, salinity, nutrient deprivation, etc.) limiting photosynthetic activity.
Plants have evolved mechanisms for acclimation to excess light and the induction of light stress proteins may be considered as a part of such protective responses.

ELIPs (Early Light-Inducible Proteins) are thylakoidal proteins widely distributed among plant species and belong to the CAB (chlorophyll $a / b$-binding protein) family (Adamska, 2001). They are synthesized as preproteins in the cytoplasm and translocated into the chloroplast where the transit 
peptide is processed. The mature forms are localised in the stroma lamellae, where they are anchored to thylakoid membranes via three transmembrane domains (Adamska and Kloppstech, 1991). ELIPs, in contrast to light-harvesting CAB proteins which are constitutively expressed, are transiently expressed: the transcript and protein appear during the early stages of deetiolation and disappear before chloroplast development is completed (Meyer and Kloppstech, 1984; Grimm and Kloppstech, 1987; Adamska, 1995; Harari-Steinberg et al., 2001). In mature plants, ELIPs are not detectable until plants are exposed to a number of environmental conditions (high light, UV, cold, salt stress, nutrient deprivation, senescence) that inhibit photosynthetic activity (Adamska et al., 1992a, b; Pötter and Kloppstech, 1993; Adamska and Kloppstech, 1994; Lindahl et al., 1997; Montané et al., 1997, 1998, 1999; Bei-Paraskevopoulou and Kloppstech, 1999). Furthermore, the chaos mutant of Arabidopsis, which is unable to accumulate ELIPs during light stress, suffers of extensive photooxidative damage when exposed to chilling in high light (Hutin et al., 2003). On this basis and taking into account that a partially purified ELIP fraction from pea contains chlorophyll $a$ and lutein (Adamska et al., 1999), it was proposed that ELIPs fulfil a protective function within the thylakoids by binding free chlorophylls released during photoinhibition in high light. Moreover, since ELIPs are transiently expressed during chloroplast development and during stress conditions that lead to an enhanced turnover of pigmentbinding proteins, an involvement of ELIPs in stabilisation of proper assembly for those proteins has also been proposed (Hutin et al., 2003).

So far, the ELIP expression pattern was most studied in Pisum sativum where the protein is encoded by a single gene (Kolanus et al., 1987), while in other species two Elip genes (or two small gene families, as in Hordeum vulgare, Grimm et al., 1989) exist coding for two ELIP proteins slightly different in molecular weight. Evidence is available that the expression of the two genes is differentially regulated: in Arabidopsis thaliana seedlings, kept in the dark or exposed to light, the transcription of Elipl is strictly light dependent while that of Elip2 occurs also in the dark (Harari-Steinberg et al., 2001). In Tortula ruralis, a desiccation-tolerant bryophyte capable of surviving desiccation, the Elipa and Elipb genes are differentially expressed in response to desiccation, rehydration, salinity, ABA and high light (Zeng et al., 2002).

However in spite of extensive research, the precise physiological function and molecular role of ELIPs is still unclear, as well is unknown if the products of the two Elip genes, when they exist, have the same or a different function. To help in answering these questions, we studied the expression of ELIPs in A. thaliana plants null for Elipl or Elip2 and analyzed the phenotype of the two null mutants during deetiolation and short-term photoinhibition.

\section{Materials and methods}

\section{Plant material and growth conditions}

The A. thaliana Col-0 line was provided by the Arabidopsis Biological Resource Center (Ohio State University, USA). The mutant lines carrying a T-DNA insertion within the Elip genes (Elip1 At3g22840, Elip2 At4g14690) were obtained from two different collections. The line GARLIC 691E05 (KO for the gene Elipl) was obtained from the Syngenta Arabidopsis Insertion Library or "SAIL" (formerly GARLIC) Collection (Sessions et al., 2002); the line 369A04 (KO for the gene Elipl) and the lines 252D03 and 292H03 (KO for the gene Elip2) were provided by Bernd Weisshaar (MPI for Plant Breeding Research, Colonia, Germany) and generated in the context of the GABI-Kat program (Rosso et al., 2003).

Plants were grown in sterilized soil (Technic n.1, Dueemme, Reggio Emilia, Italy) on Aratrays (BetaTech, Ghent, Belgium) under a $14 \mathrm{~h} \mathrm{light/}$ $10 \mathrm{~h}$ dark regime. Light was set at $120 \mu \mathrm{E} / \mathrm{m}^{2} \mathrm{~s}$ (Lumilux L36W/21, Osram, Milano, Italy) and temperature between 20 and $25^{\circ} \mathrm{C}$. Etiolated seedlings were obtained by growing sterilized seeds on AIS medium in magenta boxes for 5 days in darkness. Thereafter, they were exposed to continuous light (Microclima MC1750E, Snijders Scientific, Tilburg, Holland) for $48 \mathrm{~h}$ at room temperature $\left(25^{\circ} \mathrm{C}\right)$.

\section{Photoinhibitory treatments}

Detached leaves were placed in Petri dishes floating on water in a cabinet and exposed to different 
light intensities (measured at the level of the leaves) provided by a $400 \mathrm{~W}$ lamp (Osram HQI-E Power star, Milano, Italy). At the level of the dishes the temperature was maintained at $4{ }^{\circ} \mathrm{C}$ (for chilling treatments) or at $22{ }^{\circ} \mathrm{C}$ (for room temperature treatments) by passing the light through $5 \mathrm{~cm}$ of water and by refrigerating the cabinet and the platform bearing the dishes with circulating cold water. The extent of photoinhibition was measured as the ratio $\mathrm{Fv} / \mathrm{Fm}$ (maximum quantum yield of photosystem II) with a Plant Efficiency Analyser (PEA, Hansatech Ltd, King's Lynn, Norfolk, England) after 20 min of incubation of the leaves in the dark.

\section{Chlorophyll measurement}

Chlorophyll content of greening seedlings was calculated from the absorbance at 664, 647 and $750 \mathrm{~nm}$ (V-530 Jasco Spectrophotometer, Sintak S.r.l., Italy) of an $N, N$-dimethylformamide extract, according to Porra et al. (1989), while the chlorophyll concentration in crude protein extracts was measured according to Arnon (1949).

\section{$D N A$ and $R N A$ isolation and analysis}

Genomic DNA was extracted from leaves as described in Geuna et al. (2000). For the validation of the KO mutants, PCR analysis was performed using different combinations of the following primers:

For Elip1 5' primers: FE1g, 5'-ATCAGTCTTCGCCGGTGGAT-3'

E1F, 5'-CTAAGCTTTAGAAATGGCAACAGCAT-3'

$3^{\prime}$ primers: E1R, 5'-ACACACAGTAGGCCTAACACAGAT-3'

RE1g, 5'-GCAAGTGTCAAGATCGCTGTT-3' RTE1R, 5'-AGACGAGTGTCCCACCTTTGACGAA-3'

For Elip2 5' primers: UPE2, 5'-GTTTAGCGTTCAACCCAAATATCGAT-3'

E2F, 5'-ATCAGAAATGGCAACGGCGTCGTT-3'

$3^{\prime}$ primers: E2R, 5'-ACTAGAGTCCCACCAGTGACGTA-3'

IIESr2, 5'-GGTCGAGGGCACAGAAGGATCTT-3'
For T-DNA left border: o8409, 5'-ATATTGACCATCATACTCATTGC-3'

Total RNA was isolated from frozen material (leaves or etiolated seedlings) using Trizol (TRI$\mathrm{zol}^{\circledR}$ Reagent, Invitrogend Life Technologies S.r.l., Italy). Transcript levels were analyzed by RT-PCR (Access RT-PCR System, Promega, USA) using FE1g/E1R for Elip1, E2F/E2R for Elip 2 and Tubulin $\beta 4$ as constitutive control (5' primer: tubF, 5'-AGAGGTTGACGAGCAGATGA-3' and $3^{\prime}$ primer: tubR, 5'-CCTCTTCTTCCTCCTCGTAC- $3^{\prime}$ ). Lengths of amplification fragments were deduced by comparison with $1 \mathrm{~Kb}$ ladder (GIBCO-BRL, Italy) after electrophoresis in agarose gel. Preliminary experiments in which RT-PCR amplifications were performed for a different number of cycles were run to be sure that the intensities of the obtained bands remained well below the maximal intensities.

\section{Protein isolation and analysis}

Crude protein extracts were prepared as described in Pötter and Kloppstech (1993). Protein concentration was measured using the Lowry procedure (Sigma Diagnostic Protein Assay kit). Etiolated seedling samples equivalent to $25 \mu \mathrm{g}$ protein and leaves samples equivalent to $2 \mu \mathrm{g}$ chlorophyll were loaded in the wells. Proteins were separated by SDS-PAGE using $15 \%$ polyacrylamide gels in $6 \mathrm{M}$ urea (Laemmli discontinuous buffer system) and transferred on PVDF membrane (BioTrace ${ }^{\mathrm{TM}}$, PALL Gelman Laboratory, USA). The primary polyclonal antibody was produced in rabbit by Primm S.r.l. (Italy) using the recombinant fusion protein GST-ELIP1 as antigen. Anti-LHCII, kindly provided by dr. Laura Finzi (Dept Biology, Univ. Milano, Italy), was against a 13 aa peptide of the stromatic loop of spinach LHCB1. The secondary antibody was a peroxidase-conjugated goat anti-rabbit immunoglobulin (DakoCitomation, Denmark). Signals were detected with the Supersignal ${ }^{\circledR}$ West Pico Chemioluminescent Substrate (Pierce-CELBIO S.r.l., Italy).

\section{Production of recombinant GST-ELIP1}

The cDNA encoding the mature form of ELIP1 from $A$. thaliana (provided by Prof. Bassi, Verona, 
Italy) was cloned ( $\mathrm{NcoI} / \mathrm{EcoRI})$ in an expression vector, which derives from the pGEX-2TK (Amersham Biosciences Europe $\mathrm{GmbH}$, Italy) modified by inserting a linker via PCR disrupting the recognition sequence of BamHI and inserting that for NcoI in the MCS. Transformed BL21(DE3)pLysS E. coli cells (Stratagene, USA) grown at $28{ }^{\circ} \mathrm{C}$ in $\mathrm{LB}$ medium where induced at $\mathrm{OD}_{600}>0.9$ by adding $0.1 \mathrm{mM}$ IPTG. After $1 \mathrm{~h}$ induction, cells were harvested and fusion protein was purified by affinity chromatography on Glutathione Sepharose ${ }^{\mathrm{TM}}$ 4B (Amersham Biosciences Europe $\mathrm{GmbH}$, Italy) following the manufacture's instructions.

\section{Results}

Isolation of $\mathrm{A}$. thaliana elip1 and elip2 mutants

Screening of the two collections of $A$. thaliana insertion mutants (see Materials and methods) identified four lines carrying a T-DNA insertion in the Elip genes. The lines 691E05 and 369A04 are predicted to carry a T-DNA insertion in the Elip 1 gene, within the first intron and at the beginning of the third exon, respectively. The lines 252D03 and 292H03 have a T-DNA insertion in the Elip 2 gene, at the end of the third exon and at the beginning of the first intron, respectively. Figure 1 shows the exon/intron organization of the Arabidopsis Elip1 and Elip 2 genes, the position of the primers used for PCR and RT-PCR analysis and the location of T-DNA insertions in the mutant lines.

In order to extract from these lines homozygous knock out Elip mutants, PCR analysis on genomic DNA was performed on individual plants of the four mutant lines, using different combinations of gene and T-DNA left border specific primers. For analysis of each insertion mutant, Col-0 was the wild type control plant. For every line a few plants that were heterozygous for the insertion have been identified. Their progeny was screened and at least one homozygous plant for each insertion line has been isolated. To confirm even the absence of the transcript, RT-PCR on total RNA was performed. For simplicity these plants were named as follows: E05 and A04 (KO mutants for Elip1); D03 and H03 (KO mutants for Elip2). Since all mutant lines were similarly screened, only the analysis of the line A04 is shown in Figure 2. The homozygous presence of the T-DNA in the third exon of Elip1 is supported by the absence in the mutant line of an amplification product when performing PCR analysis using gene specific primers located upstream and downstream of the insertion (Figure 2A) and by the presence of a band corresponding to the T-DNA flanking region when using a $5^{\prime}$-gene specific primer and a primer annealing to the LB of

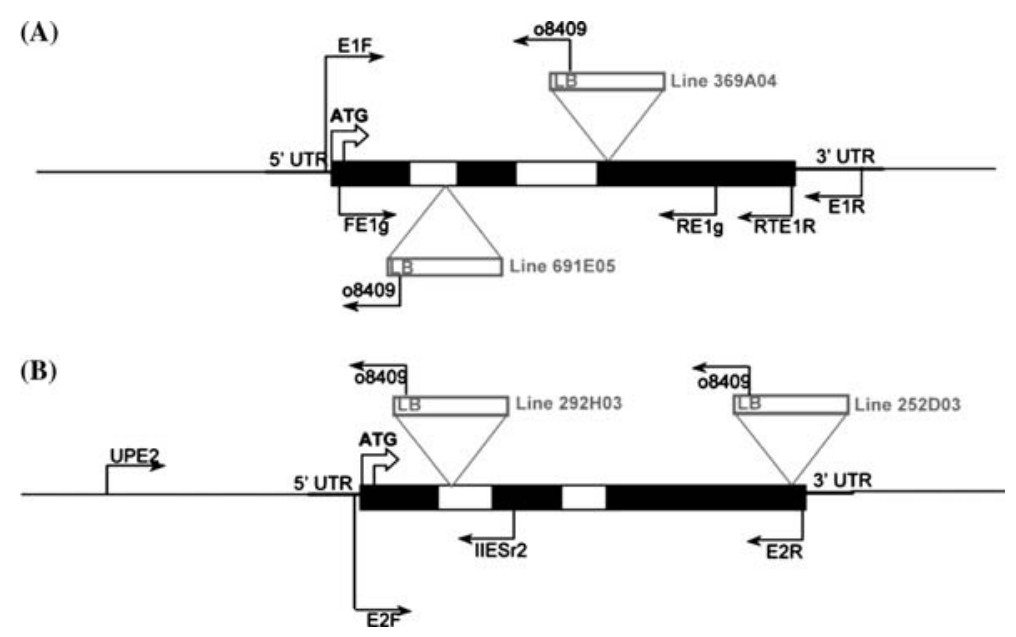

Figure 1. Schematic representation of Elip genes from A. thaliana: Elip1 (A) and Elip2 (B). Introns are shown as white boxes, exons as black boxes. The organisation of T-DNA insertions and orientation in the four mutant lines are shown in grey, while the black arrows indicate the annealing position of the primers used for PCR and RT-PCR analysis. 


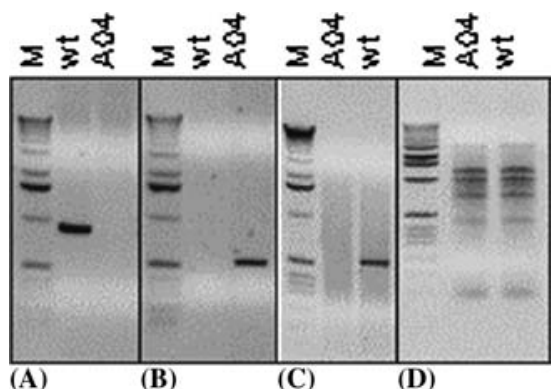

Figure 2. Validation of the mutant line A04 (KO for Elip1). PCR amplification on genomic DNA of (A) the whole coding sequence for Elip1 ( $\sim 920$ bp, primers E1F and E1R) and (B) the T-DNA flanking region $(\sim 535 \mathrm{bp}$, primers 08409 and FE1g). (C) Amplification of the whole transcript for Elip1 ( $\sim 580 \mathrm{bp}$, FE1g and RT-E1R) by RT-PCR on total RNA. The quality of extracted RNA can be deduced by the ethidium bromide-stained agarose gel shown in (D). $\mathrm{M}=$ marker.

the T-DNA (Figure 2B). The absence of the transcript for Elip1 in the line A04, was confirmed by RT-PCR on total RNA (Figure 2C).

The validation of the mutant lines was also performed at the protein level by Western blot analysis of total protein extracts, using a polyclonal antibody against the recombinant GST-ELIP1 protein. In wild type plants exposed for a few days to high light and low temperature (Figure 3), two largely overlapping bands, with an apparent molecular weight matching that reported for ELIP1 and ELIP2 (19.5 and $16 \mathrm{kDa}$, respectively, Heddad and Adamska, 2000), were detected by the antibody. The analysis of the insertion lines (see Figure 3 for $\mathrm{A} 04$ and $\mathrm{H} 03$ lines) revealed the presence of only one of the two bands. This result enabled us not only to validate the mutant lines but also to identify the migration position of the two ELIPs in our SDS-urea polyacrylamide gels (ELIP1 migrating slightly ahead of ELIP2)

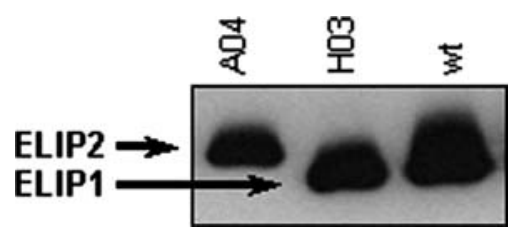

Figure 3. Validation of the KO lines and identification of ELIP1 and ELIP2 proteins. Western blot analysis was performed on total protein extracts from mutant lines (A04 and H03) and wild type plants exposed to high light intensities and low temperature. The arrows indicate the migration position of ELIP1 and ELIP2. which is the opposite of the pattern observed by Andersson et al. (2003) in SDS gels.

Noteworthy, under our standard growing conditions, plants of all four null mutants were indistinguishable from the wild type during the entire life cycle. Furthermore, since the expression pattern of transcript and protein was identical between the two elip1, as well as the two elip2 mutants, results for only a couple of them (A04 and $\mathrm{H} 03$, null for Elip1 and Elip2, respectively) are reported in the following sections.

\section{Effect of light and temperature on ELIPS transcription and accumulation}

The time course of ELIP1 and ELIP2 transcripts and proteins accumulation has been investigated in detached leaves of mature plants (wild type and null mutants) exposed to an irradiation of $750 \mu \mathrm{E} /$ $\mathrm{m}^{2} \mathrm{~s}$ (HL) at a temperature of 22 or $4{ }^{\circ} \mathrm{C}$. The decay of the maximal PSII photochemical efficiency during the treatment was followed by measuring chlorophyll variable fluorescence (Figure 4). During light stress, Fv/Fm noticeably decreased reaching a value of ca. 0.2 after $12-14 \mathrm{~h}$ of treatment and the extent of its reduction was similar between wild type and mutants either when photoinhibition was done at room temperature or in the cold.

At different times during light stress, leaves were sampled for estimation of the level of ELIPs transcript and protein. However, since it was reported that in barley and pea the level of Elip transcript fluctuates diurnally (Otto et al., 1988, Adamska et al., 1991, Pötter and Kloppstech, 1993), we included in the experiment the analysis of transcripts and proteins in leaves maintained in the growing chamber at a light intensity of $120 \mu \mathrm{E} /$ $\mathrm{m}^{2} \mathrm{~s}(\mathrm{LL})$. Samples were collected from LL and HL plants at the same times. Figure 5A (LL) shows indeed that, also in A. thaliana, the level of Elip1 and Elip2 transcript changed during the day, being at a maximum $2 \mathrm{~h}$ after turning on the light and at a minimum in the afternoon: persistency of fluctuation during constant light or dark (not shown) suggested a circadian control of Elips transcription. Exposure to high light suppressed diurnal fluctuation and the level of both Elip transcripts stayed at the daily maximum (or even more) during all the time of exposure to high light. 

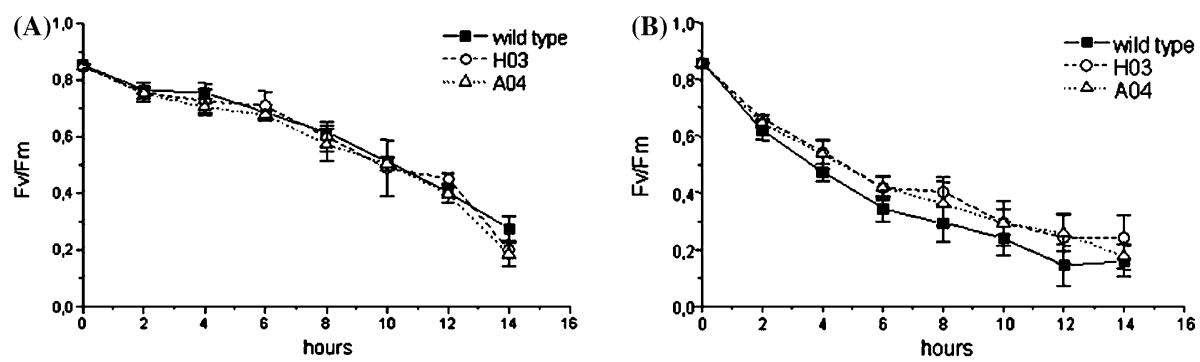

Figure 4. Reduction of maximal photochemical efficiency during photoinhibition in wild type and mutant leaves exposed to high light (A) or high light and low temperature (B).

The pattern was essentially the same at 22 or $4{ }^{\circ} \mathrm{C}$ with the level of Elip2 transcript being higher in the cold than at room temperature. Both elip1 and elip2 mutants showed the same behavior: the transcripts fluctuated diurnally and responded to high light and chilling with the same kinetic and intensity as in the wild type (data not shown).

ELIP proteins were however absent, or present at a level not detectable by the antibody, in LL plants (wild type and mutants) during the entire light period (Figure 5B and C). Exposure of the wild type to high light induced the progressive accumulation of one ELIP when the treatment was done at $22{ }^{\circ} \mathrm{C}$ and of both ELIPs when the treatment was performed at $4{ }^{\circ} \mathrm{C}$ (Figure 5B). The electrophoretic position of the band appearing at $22{ }^{\circ} \mathrm{C}$ corresponds to that of ELIP1 (see Figure 3 where ELIP1 migrates in front of ELIP2).

In the elip 2 mutant (top of Figure 5C), the only possible ELIP which can be expressed is ELIP1 and this ELIP was expressed after exposure of the plants to high light either at 22 and at $4{ }^{\circ} \mathrm{C}$; in the elip1 mutant, only ELIP2 can be produced and this ELIP appeared when the treatment was done in the cold but not at room temperature (bottom of Figure 5C). This result confirms that, in our experimental conditions, wild type plants express only ELIP1 when light stressed at $22{ }^{\circ} \mathrm{C}$ and both ELIPs when stressed at $4{ }^{\circ} \mathrm{C}$, notwithstanding the extent of $\mathrm{Fv} / \mathrm{Fm}$ decay was similar between the two treatments (see Figure 4). Furthermore, of particular interest was the observation that the sensitivity of the elipl mutant to high light at room temperature was the same as that of the wild type, even if in this condition this mutant did not accumulate any ELIP: ELIP1 due to the mutation and ELIP2 because it is not expressed at room temperature.

Dependence of transcript and protein level from light intensity and temperature is reported in Figure 6. At $22^{\circ} \mathrm{C}$, the level of Elipl transcript was already increased in leaves exposed to $250 \mu \mathrm{E} / \mathrm{m}^{2} \mathrm{~s}$ with respect to that present in growing light $\left(120 \mu \mathrm{E} / \mathrm{m}^{2} \mathrm{~s}\right)$ and a further
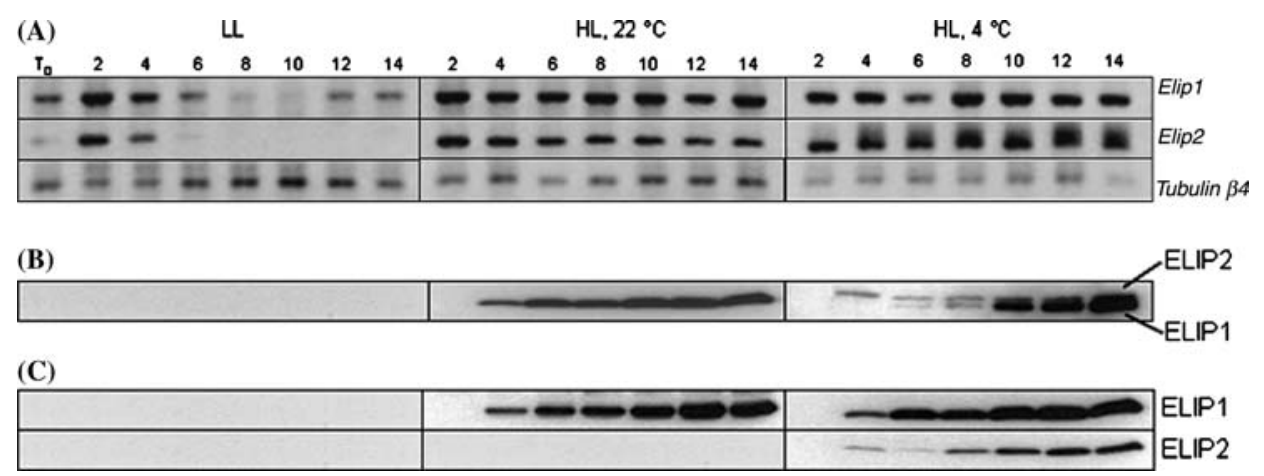

Figure 5. Kinetics of ELIPs accumulation during photoinhibitory treatments. (A) Transcripts accumulation (RT-PCR analysis) in wild type plants maintained under low light ( $\mathrm{LL}, 120 \mu \mathrm{E} / \mathrm{m}^{2} \mathrm{~s}$ ) or exposed to high light (HL, $750 \mu \mathrm{E} / \mathrm{m}^{2} \mathrm{~s}$ ) at room temperature $\left(22{ }^{\circ} \mathrm{C}\right)$ and to high light in the cold $\left(4^{\circ} \mathrm{C}\right)$. Protein levels (Western blot analysis) induced by the treatments in the wild type (B) and mutant lines H03 (top) and A04 (bottom) lacking, respectively, ELIP2 and ELIP1 (C). Samples for total RNA and protein extraction were collected at the beginning of the treatment $\left(T_{0}\right)$ and thereafter every $2 \mathrm{~h}$. 
increment was observed until $2000 \mu \mathrm{E} / \mathrm{m}^{2}$ s while at $4{ }^{\circ} \mathrm{C}$ the dependence of transcript level on light intensity was less pronounced. At $22^{\circ} \mathrm{C}$ Elip2 transcript appeared only at irradiations of $750 \mu \mathrm{E} / \mathrm{m}^{2} \mathrm{~s}$ or higher, while at $4{ }^{\circ} \mathrm{C}$ the transcript was already present in a considerable amount at $120 \mu \mathrm{E} / \mathrm{m}^{2} \mathrm{~s}$ and remained constant at higher irradiations. Again in the single mutants the level of transcript at different light intensities was the same as that observed in the wild type (data not shown).

At the protein level, in the elip2 mutant ELIP1 appeared at 22 and $4{ }^{\circ} \mathrm{C}$ after exposure of the leaves at a light intensity of $250 \mu \mathrm{E} / \mathrm{m}^{2} \mathrm{~s}$ and then accumulated in a light intensity-dependent manner. In the elip1 mutant ELIP2 was not detectable at $22{ }^{\circ} \mathrm{C}$ at all light intensities assayed, while it was expressed at $4{ }^{\circ} \mathrm{C}$ in a pattern very similar to that of ELIP1. Again, the exposure to high light caused a progressive and marked inhibition of maximal photochemical efficiency, whose extent however was similar for wild type and mutants (data not shown).

\section{Kinetics of ELIPs accumulation and phenotype of the mutants during seedlings deetiolation}

Figure 7 shows the time course of ELIPs transcript and protein accumulation in seedlings of wild type and elip 1 and 2 mutants during the first $48 \mathrm{~h}$ of deetiolation in continuous light $\left(120 \mu \mathrm{E} / \mathrm{m}^{2} \mathrm{~s}\right)$. Accumulation kinetics of Elip1 and Elip2 transcripts (Figure 7A) were substantially the same: for both genes, the transcript level was very low at the beginning of greening $\left(\mathrm{T}_{0}, 5\right.$ days of growth in the dark), peaked between 4 and $8 \mathrm{~h}$ of illumination and decreased afterward, with the level of Elip1 transcript slightly more abundant than that of Elip2. Both ELIP proteins (Figure 7B), not detectable at $\mathrm{T}_{0}$, increased with time, peaking at 4-8 $\mathrm{h}$ and then disappeared. In contrast to ELIPs, LHCII proteins increased steadily during deetiolation.

During greening the chlorophyll content raised continuously in both wild type and $\mathrm{H} 03$ and A04 lines (lacking, respectively, ELIP2 and ELIP1). However after $48 \mathrm{~h}$, the level reached by both mutants, which showed a slightly pale green phenotype, was significantly lower, being about $72 \%$ of the wild type (Figure 7C). The extent of chlorophyll reduction in the mutants was dependent on light intensity during deetiolation, being more severe at high light. In fact, at $60 \mu \mathrm{E} / \mathrm{m}^{2} \mathrm{~s}$ no differences were detectable between mutants and wild type, while at $250 \mu \mathrm{E} / \mathrm{m}^{2}$ s the chlorophyll content in the mutant lines was only $16 \%$ of that reached by the wild type (data not shown). Chlorophylls $a / b$ (chl $a / b$ ) ratios were lower in the mutants in respect to the wild type especially at the highest irradiances: for example after 4 days of deetiolation chl $a / b$ ratio was around 3 for the wild type at all light intensities, while it was 2.6 at $60 \mu \mathrm{E} / \mathrm{m}^{2}$ s and 1.9 at 120 and $250 \mu \mathrm{E} / \mathrm{m}^{2} \mathrm{~s}$ for the two mutants.

It should be underlined however that when deetiolation was conducted in $14 \mathrm{~h}$ light/10 h dark cycle, instead of continuous light, mutants were green and not distinguishable from the wild type, even at the highest irradiation assayed (data not shown).

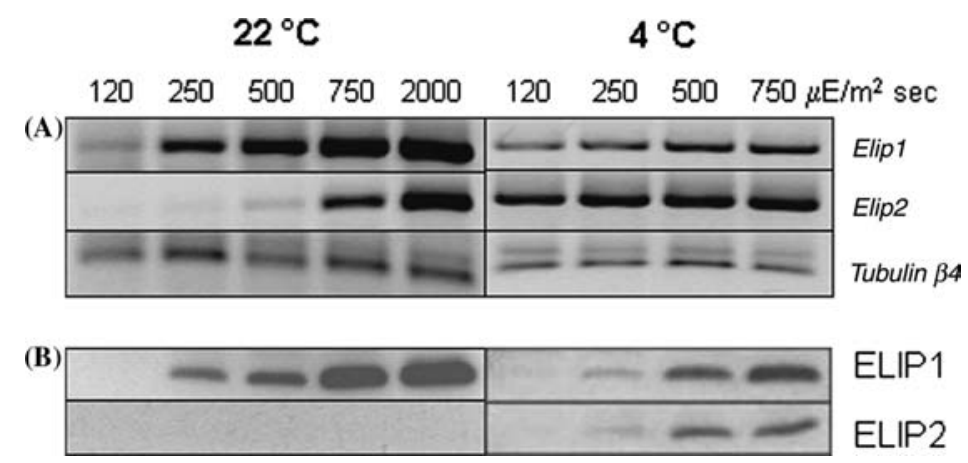

Figure 6. ELIPs accumulation in leaves of mature plants exposed to increasing light intensities at 22 and $4{ }^{\circ} \mathrm{C}$. Detached leaves from dark adapted plants were floated on water and irradiated with the indicated light intensities. After $6 \mathrm{~h}$ samples were collected for total RNA and protein extraction. RT-PCR analysis in wild type plants is shown in (A) (Tubulin $\beta 4$ was used as constitutive control) and the Western blot analysis for mutant lines lacking ELIP2 (top) and ELIP1 (bottom) in (B). 

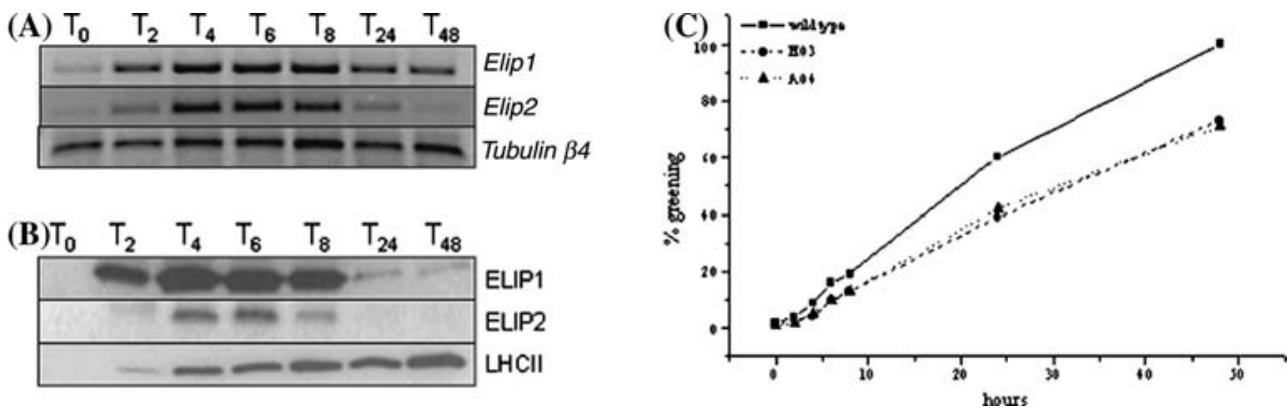

Figure 7. Kinetics of ELIPs accumulation during greening of etiolated seedlings. Seeds of wild type and mutant lines (H03 and A04) were grown for 5 days in the dark $\left(T_{0}\right)$ and then transferred to continuous light $\left(120 \mu \mathrm{E} / \mathrm{m}^{2} \mathrm{~s}\right)$ for $48 \mathrm{~h}$. At the given times samples were collected for RNA and protein extractions and chlorophyll measurements. (A) RT-PCR analysis on total RNA extracted from wild type seedlings for Elip1 and Elip2 transcripts (Tubulin $\beta 4$ was used as constitutive control). (B) Western blot analysis on total proteins extracted from H03 (for ELIP1), A04 (for ELIP2) and wild type seedlings (for LHCII). (C) Chlorophyll (Chl) data are presented as percentage of the Chl level reached by the wild type after $48 \mathrm{~h}$ of greening ( $242 \mu \mathrm{g}$ total $\mathrm{Chl} / \mathrm{g}$ fresh weight). SE $\pm 5 \%$ of the reported values.

\section{Discussion}

In the present work we took the advantage of the elipl and 2 mutants to analyze the expression profile, at the level of transcripts and proteins, of the two A. thaliana Elip genes (Elip1 and Elip2). This has been feasible because:

(i) Elip1 and Elip2 transcripts can be discriminated in wild type plants using, in a RT-PCR reaction, primers specific for each gene;

(ii) ELIP proteins, which in wild type plants largely overlap after urea-SDS-PAGE, can be separately identified in elip1 or elip 2 mutants.

Furthermore, under standard growing conditions, the mutants behave as the wild type, making the study of ELIPs expression profile physiologically meaningful. As a matter of fact, we never observed in our mutants any kind of compensation in the level of transcript or protein of one ELIP in the absence of the other.

In mature light/dark grown plants exposed to low light, the level of Elip1 and Elip2 transcripts varies during the day reaching a maximum two hours after the onset of light and a minimum in the afternoon. Oscillations in the level of Elip transcripts have been already reported in other species (Otto et al., 1988; Adamska et al., 1991; Pötter and Kloppstech, 1993) and attributed to the presence of a circadian control. This type of regulation is actually predictable, since the genomic sequence of both Elip genes contains circadian regulatory elements (the "CAANNN-
NATC" and "GATA" motives) in the 5'-upstream region, which are present and conserved in clock controlled Lhc genes (Piechulla et al., 1998). The presence of transcripts however is not accompanied by the presence of the corresponding proteins during the entire light period (or even during the night). This finding cannot be attributed to a level of protein too low to be detected by the antibody, because in the presence of comparable amounts of transcripts, both ELIPs can be detected (compare for example the band intensity of the Elipl transcript at $2 \mathrm{~h}$ in $\mathrm{LL} v s$ that at $6 \mathrm{~h}$ in $\mathrm{HL}$ plants at $22^{\circ} \mathrm{C}$ and the corresponding level of protein in Figure 5). It could be that in LL plants a mechanism suppressing Elip mRNAs translation is active or that proteins are produced but rapidly degraded.

From our data, conditions able to overwhelm the diurnal fluctuation of the Elip transcript and to induce the accumulation of transcript and protein are the exposure of mature plants to light intensities higher than the growing one or to low temperature, and the greening process in etiolated seedlings exposed to continuous light. These results are in some way expected since they confirm what was already reported in literature (Cronshagen and Herzfeld, 1990; Pötter and Kloppstech, 1993; Adamska et al., 1992b, 1993). What is not expected is that, upon light exposure at $22{ }^{\circ} \mathrm{C}$, only ELIP1 accumulates and not ELIP2. This conclusion is based on the appearance of a single ELIP migrating in a position corresponding to that of ELIP1 in wild type plants light stressed 
at $22{ }^{\circ} \mathrm{C}$ and also on the fact that in the elipl mutant, ELIP2 is always undetectable at room temperature (see Figures 5 and 6). Expression of both ELIPs was previously reported by Andersson et al. (2003) in detached leaves of Arabidopsis exposed to light stress $\left(2500 \mu \mathrm{E} / \mathrm{m}^{2} \mathrm{~s}\right)$ for $3 \mathrm{~h}$, but, since the temperature of the water in which leaves were floated during irradiation was not indicated, it could be that leaves were subjected to light and also cold stress. What is clear is that accumulation of both ELIPs requires light (not necessarily high light) in the cold. The finding is again in favour of the presence of a type of translational or posttranslational control of ELIPs expression. In fact, light at $22{ }^{\circ} \mathrm{C}$ or $4{ }^{\circ} \mathrm{C}$ induces the accumulation of the transcript of both Elips (to an extent proportional to light intensity, even if with a different sensitivity between the two genes) but only one protein is expressed at $22{ }^{\circ} \mathrm{C}$ and both in the cold. Apparently, a control mechanism exists able to discriminate at room temperature which one of the two transcripts should be translated, or which one of the two proteins should be saved. Furthermore, even the transcription of the Elip genes should be in some way differently regulated: at $22^{\circ} \mathrm{C}$ the light intensity threshold for induction of Elipl is much lower than that of Elip2 and in the cold Elip2 is highly expressed at all light intensities. These findings imply that the perception of the signals inducing the transcription and synthesis of ELIP1 and ELIP2 should be different and under the control of at least in part independent pathways, as already suggested for Elips transcription by Harari-Steinberg et al. (2001) in A. thaliana and by Zeng et al. (2002) in Tortula ruralis.

Do these observations give us some cues about ELIPs function? From our data it seems that in mature plants ELIPs do not have a direct role in photoprotection. In fact, under light stress at room temperature or in the cold the single mutants behave as the wild type (at least judging from the extent of photoinhibition). While in the cold the presence of one or the other ELIP can be sufficient to phenocopy the photosensitivity of the wild type, this cannot be possible at room temperature where the elip1 mutant misses both ELIPs: nevertheless its sensitivity to light stress is the same as that of the wild type. This conclusion is apparently in contrast with what reported by Hutin et al. (2003) in the chaos mutant of $A$. thaliana. This mutant, altered in the posttranslational targeting of light-harvesting complex proteins to the thylakoids, lacks both ELIPs together with a substantial reduction of LHCII proteins and shows enhanced sensitivity to light stress. Restored phototolerance is achieved in chaos by overexpressing ELIP1 or ELIP2. It should be noted however that significant differences between chaos and wild type are detectable only after 2 or more days of photoinhibitory treatment while our experiments lasted $14 \mathrm{~h}$ at maximum. In short-term treatments chaos and our mutants behave as the wild type. Prolonged treatments in the cold or at room temperature and the availability of a double elip1/elip2 mutant will allow us to address in detail this topic.

elip1 and elip2 mutants differ instead from the wild type in the rate of chlorophyll accumulation during the process of deetiolation in continuous light, being the rate more and more reduced as the light intensity increases and with chl $a$ accumulation more affected than $\operatorname{chl} b$. Furthermore, the extent of reduction is identical independently if Elip1 or Elip2 genes are knocked out. These results indicate that photoprotection is insufficient in the mutant seedlings during greening. It should be noted however that when deetiolation is done in a light/dark cycle, which is a more natural condition, the mutants behave as the wild type. So, both ELIPs seem to be necessary only when seedlings are experiencing the extreme condition of greening in strong and continuous light. As a matter of facts, ELIPs accumulate during the first stages of greening in parallel with the reaction centre proteins but before all the other pigment binding proteins of the antennae and then disappears once the photosystems are completely assembled (Król et al., 1999; Guseinova et al., 2001). It seems therefore reasonable that ELIPs must play a crucial role at this step: they could temporary bind free pigments, continuously produced in light, until antenna proteins are synthesized, protecting them from photooxidation, or they could somehow assist proper assembly of pigment binding proteins.

\section{Acknowledgements}

We are grateful to Prof. Roberto Bassi (Dept Sci \& Technol, University of Verona, Italy) for his suggestions at the beginning of this research and for valuable comments on the manuscript. 
We also thank Prof. Robert Jennings (Dept Biology, University of Milano, Italy) and Dr Paolo Pesaresi (Max Planck Inst Zuchtungsforsch, Cologne, Germany) for critical reading of the manuscript. We are indebted to Syngenta Biotechnology, Inc. (SBI) and the GABI-Kat program for providing us with the mutant lines. Financial support was in part from MIUR (FIRB project No. RBAU01E3CX) and in part from Institute of Biophysics - Division Research Milano - CNR - Italy.

\section{References}

Adamska, I., Scheel, B. and Kloppstech, K. 1991. Circadian oscillations of nuclear-encoded chloroplast proteins in pea (Pisum sativum). Plant Mol. Biol. 17: 1055-1065.

Adamska, I. and Kloppstech, K. 1991. Evidence for an association of the early light-inducible protein (ELIP) of pea with photosystem II. Plant Mol. Biol. 16: 209-223.

Adamska, I., Kloppstech, K. and Ohad, I. 1992a. UV light stress induces the synthesis of the early light-inducible protein and prevents its degradation. J. Biol. Chem. 267/ 34: 24732-24737.

Adamska, I., Ohad, I. and Kloppstech, K. 1992b. Synthesis of the early light-inducible protein is controlled by blue light and related to light stress. Proc. Natl Acad. Sci. USA 89: 2610-2613.

Adamska, I., Kloppstech, K. and Ohad, I. 1993. Early lightinducible protein in pea is stable during light stress but is degraded during recovery at low light intensity. J. Biol. Chem. 268/8: 5438-5444.

Adamska, I. and Kloppstech, K. 1994. Low temperature increases the abundance of early light-inducible transcript under light stress conditions. J. Biol. Chem. 269/48: 3022130226.

Adamska, I. 1995. Regulation of early light-inducible protein gene expression by blue and red light in etiolated seedlings involves nuclear and plastid factors. Plant Physiol. 107: $1167-1175$.

Adamska, I., Roobol-Bóza, M., Lindahl, M. and Andersson, B. 1999. Isolation of pigment-binding early light-inducible proteins from pea. Eur. J. Biochem. 260: 453-460.

Adamska I., 2001. The Elip family of stress proteins in the thylakoid membranes of Pro- and Eukaryota. In: E-M. Aro, B. Andersson (Eds.), Regulation of Photosynthesis, Kluwer Academic Publishers, 11, pp. 487-505.

Andersson, U., Heddad, M. and Adamska, I. 2003. Light stress-induced one-helix protein of the chlorophyll $a / b$ binding family associated with photosystem I. Plant Physiol 132: 811-820.

Arnon, D.I. 1949. Copper enzymes in isolated chloroplasts: polyphenol oxidase in Beta vulgaris. Plant Physiol. 24: 1-15.

Bei-Paraskevopoulou, T. and Kloppstech, K. 1999. The expression of early light-inducible proteins (ELIPs) under high-light stress as defense marker in Northern- and Southern European cultivars of barley (Hordeum vulgare). Physiol. Plant. 106: 105-111.
Geuna, J., Hartings, H. and Scienza, A. 2000. Plant DNA extraction based on grinding by reciprocal shaking of dried tissue. Anal. Biochem. 278: 228-230.

Grimm, B. and Kloppstech, K. 1987. The early light-inducible proteins of barley. Eur. J. Biochem. 167: 493-499.

Grimm, B., Kruse, E. and Kloppstech, K. 1989. Transiently expressed early light-inducible thylakoid proteins share transmembrane domains with light-harvesting chlorophyll binding proteins. Plant Mol. Biol. 13/5: 583-593.

Guseinova, I.N., Suleimanov, S.Y., Zulfugarov, I.S. and Aliev, J.A. 2001. Assembly of the light-harvesting complexes during plastid development. J. Fluor. 10/3: 255-259.

Harari-Steinberg, O., Ohad, I. and . Chamovitz, D. A 2001. Dissection of the light signal transduction pathways regulating the two early light-induced protein genes in Arabidopsis. Plant Physiol. 127: 986-997.

Heddad, M. and Adamska, I. 2000. Light stress-regulated twohelix proteins in Arabidopsis thaliana related to the chlorophyll $a / b$-binding gene family. Proc. Natl Acad. Sci. USA 977: 3741-3746.

Hutin, C., Nussaume, L., Moise, N., Moya, I., Kloppstech, K. and Havaux, M. 2003. Early light-induced proteins protect Arabidopsis from photooxidative stress. Proc. Natl Acad. Sci. USA 1008: 4921-4926.

Kolanus, W., Scharnhorst, C., Kuehne, U. and Herzfeld, F. 1987. The structure and light-dependent transient expression of a nuclear-encoded chloroplast protein gene from pea (Pisum sativum L.). Mol. Gen. Genet. 209: 234-239.

Król, M., Ivanov, A.G., Jansson, S., Kloppstech, K. and Huner, N.P.A. 1999. Greening under high light or cold temperature affects level of xantophyll-cycle pigments, early light-inducible proteins, and light-harvesting polypeptides in wild-type barley and the chlorina $f 2$ mutant. Plant Physiol. 120: 193-203.

Lindahl, M., Funk, C., Webster, J., Bingsmark, S., Adamska, I. and Andersson, B. 1997. Expression of ELIPs and PSII-S protein in spinach during acclimative reduction of the photosystem II antenna in response to increased light intensities. Photosynth. Res. 54: 227-236.

Meyer, G. and Kloppstech, K. 1984. A rapidly light-induced chloroplast protein with a high turnover coded for by pea nuclear DNA. Eur. J. Biochem. 138: 201-207.

Montané, M.H., Dreyer, S., Triantaphylides, C. and Kloppstech, K. 1997. Early light-inducible proteins during long-term acclimation of barley to photooxidative stress caused by light and cold:high level of accumulation by posttranscriptional regulation. Planta 202: 293-302.

Montané, M.H., Tardy, F., Kloppstech, K. and Havaux, M. 1998. Differential control of xanthophylls and lightinduced stress proteins, as opposed to light-harvesting chlorophyll $\mathrm{a} / \mathrm{b}$ proteins, during photosynthetic acclimation of barley leaves to light irradiance. Plant Physiol. 118: 227-235.

Montané, M.H., Petzold, B. and Kloppstech, K. 1999. Formation of early-light-inducible-protein complexes and status of xanthophyll level under high light and cold stress in barley (Hordeum vulgare L.). Planta 208: 519-527.

Otto, B., Grimm, B., Ottersbach, P. and Kloppstech, K. 1988. Circadian control of the accumulation of mRNAs for lightand heat-inducible chloroplast proteins in pea (Pisum sativum L.). Plant Physiol. 88: 21-25.

Piechulla, B., Merforth, N. and Rudolph, B. 1998. Identification of tomato Lhc promoter regions necessary for circadian expression. Plant Mol. Biol. 38: 655-662. 
Porra, R.J., Thompson, W.A. and Kriedermann, P.E. 1989 Determination of accurate extinction coefficients and simultaneous equation for assaying chlorophylls $a$ and $b$ extracted with four different solvents: verification of the concentration of chlorophyll standards by atomic absorption spectroscopy. Biochim. Biophys. Acta 975: 384-394.

Pötter, E. and Kloppstech, K. 1993. Effects of light stress on the expression of early light-inducible proteins in barley. Eur. J. Biochem. 214: 779-786.

Rosso, M.G., Li, Y., Strizhov, N., Reiss, B., Dekker, K. and Weisshaar, B. 2003. An Arabidopsis thaliana T-DNA mutagenized population (GABI-Kat) for flanking sequence tag-based reverse genetics. Plant Mol. Biol. 53: 247-259.
Sessions, A., Burke, E., Presting, G., Aux, G., McElver, J., Patton, D., Dietrich, B., Ho, P., Bacwaden, J., Ko, C., Clarke, JD., Cotton, D., Bullis, D., Snell, J., Miguel, T., Hutchison, D., Kimmerly, B., Mitzel, T., Katagiri, F., Glazebrook, J., Law, M. and Goff, SA. 2002. A highthroughput Arabidopsis reverse genetics system. Plant Cell 14: 2985-2994

Zeng, O., Chen, X.B. and Wood A.J., 2002. Two early lightinducible protein (ELIP) cDNAs from the resurrection plant Tortula ruralis are differentially expressed in response to dessication, rehydration, salinity, and high light. J. Exp. Bot. 53/371: 1197-1205. 